\title{
Tetabuk Özelliği Olan Sahte İmzaların Tespitinde Bilgisayar Teknolojilerinin Rolü: Olgu Sunumu
}

\author{
The Role of Computer Technology in Detection of Forged Signatures having Overlapping \\ Features: Case Report
}

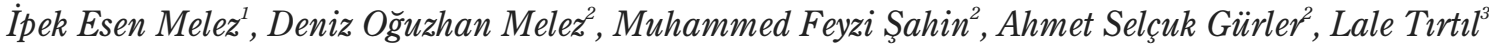

${ }^{1}$ Bezmialem Vakıf Üniversitesi Tip Fakültesi Adli Tip Anabilim Dah, İstanbul

${ }^{2}$ Adalet Bakanlı̆̆ , Adli Tip Kurumu, İstanbul

${ }^{3}$ Adalet Bakanliğı, Adli Tip Kurumu, Büyükçekmece Adli Tip Şube Müdürlüğ̈̈, İstanbul

\section{Özet}

İmza, kişisel özellikleri yansıtan ve yasal olarak kişiye özel olduğu kabul edilen bir el yazısı biçimidir. İmza sahteciliğinde birçok yöntem kullanılabilmekte olup karbon kağıdı kullanılarak kopyalama bu yöntemlerden biridir. Bu çalıșmada, karbon kağıdı kullanılarak kopyalama içeren bir imza sahteciliği olgusu irdelenerek, imzaların bilgisayar ortamında süperimpozisyonu (üst üste getirilmesi) yöntemi ile tetabukun gösterilmesi ve olgu üzerinden belge incelemede tetabuk ayırıcı tanısı ile birlikte bilgisayar teknolojilerinin rolünün tartışılması amaçlanmıştır. Güncel belge inceleme bilirkişiliği açısından, kişisel tecrübenin yanı sıra bilgisayar teknolojileri de analizde önem kazanmaktadır. Hayatın doğal akışına uygun görünmeyen biçimde birbirinin aynı olan iki imza ya da imza grubu (tetabuk) arasında olası sahtecilik unsurlarının değerlendirilmesinde, süperimpozisyon yönteminin salt kişisel gözlem sonuçları dışında lineer matematik verilerle de ortaya konulabilir şekilde uygulanması için pahalı bilgisayar programlarının yanında daha basit ama ücretsiz, açık kaynak kodlu programların da kullanılabileceğini göstermek açısından bu olgu ve olgunun çözümlenme yolu bilimsel paylaşıma değer bulunmuştur.

Anahtar Kelimeler: Belge inceleme, İmza inceleme, Bilgisayar teknolojisi, Süperimpozisyon, Tetabuk.

\section{Giriş}

İmza, el yazısının özel bir şekli olup bir kimsenin, kendisinin tanınmasını sağlamak için, kendi kaligrafik ve karakteristik özelliklerini yansitarak oluşturduğu el yazısıdır $(1,2)$. El yazısından daha hızlı ve otomatize bir şekilde oluşturulması nedeni ile kişiye özgü özellikler içermesi daha beklenir bir sonuçtur $(3,4)$. Yasa koyucu tarafından, bulunduğu belgedeki beyan ve yükümlülüklerinin kişi tarafından kabul edildiğinin bir göstergesi olarak kabul görmesi de imzaya ayrı bir önem katmaktadır (1,4). Yasalar karşısında bu kadar güçlü bir unsur olması, istismar edilmesini beraberinde getirmektedir $(4,5,6)$.

Sorumlu yazar: Yrd.Doc.Dr. İpek Esen Melez

Bezmialem Vakıf Üniversitesi Tip Fakültesi

Adli Tip Anabilim Dal, İstanbul

E-mail: ipekesen@gmail.com

\section{Abstract}

Signature is a handwriting type which reflects the personal characteristics and which is legally accepted to be exclusive. Various methods can be used for signature forgery and copying through carbon paper use is one of these methods. In this study, to show 'overlapping' with the method of superimposition of the signatures in computer media through analyzing the case of a signature forgery which includes the method of copying through carbon paper use and to discuss the role of computer technologies together with the differential diagnosis of 'overlapping' in document examination have been aimed. With regards to contemporary document examination expertise, besides personal experience, also computer technologies are becoming important in the analysis. In the evaluation of forgery components between two signatures or signature groups being identical to a degree which seems to be impossible in the nature of things (overlapping), this case and the way of its analysis is found to be worth being scientifically shared in order to show that not only expensive computer programs but also free, open source softwares can be used for carrying out superimposition method in a way possible to present through linear mathematics data instead of only personal observation results.

Keywords: Document examination, Signature examination; Computer technology, Superimposition, Overlapping.

İstismar sonucu ortaya çıkan sahtecilik, belgenin tamamının sahte olduğu "tam sahtecilik", belge üzerinde tahrifat ve değişiklik yapmak sureti olan "kısmi sahtecilik" olarak ikiye ayrılabilir. Sahtecilik türleri arasında ise en sik karşımıza çıkan imzanın taklidi yolu ile yapılan tam sahteciliktir.

İmza taklidi için farklı yöntemler kullanılmaktadır. Bunlar;

$\square$ Serbest taklityöntemi

૫Bakarak taklityöntemi

口 Üstten gitme yöntemi

૫ Karbon kâğıdı kullanılarak kopya yöntemi

$\square$ Kalem bası izi(fulaj) yöntemi ile kopyalama

$\checkmark$ Pul transferi yöntemi

$\square$ Belgeye transfer (fotokopi, tarayıcı, dijital fotoğraflama)

૫ Uydurmayöntemi

$\square$ İnkâr kastı ile atılan imza yöntemi

$\square$ İmza makinesi $(2,3,7)$ 
Tüm belge sahteciliklerinde olduğu gibi imza sahteciliği tespitinde kullanılan yöntemler, teknolojinin gelişmesi ile çeşitlenmiş ve buna paralel olarak doğruya ulaşma sayı ve kalitesi artmıştır $(8,9)$.

Üstten gitme, karbon kağıdı kullanılarak kopyalama ve belgeye transfer biçiminde gerçekleştirilen sahtecilik yöntemlerinin değerlendirilmesinde temel kriter, kişinin imzasını, tüm özellikleri ile bir kez daha atmasının dolayısıyla tetabukun (uyumun, üst üste çakışmanın) mümkün olmadığıdır $(1,10,11)$. İmzanın asıl sahibi tarafından atılan belgedeki imza ile inceleme konusu olan imza arasındaki tetabuku (uyum, üst üste çakışma), süperimpozisyon(üst üste bindirme) yöntemi ile tespit etmek mümkündür (2-4,7). Bunun için iki imza üst üste getirilerek alttan bir 1şı kaynağı ile görüntüler arasında birebir çakışma olup olmadığına bakılabilir. Ancak, tetabuk varlığının salt gözlem dışında lineer matematik verileri ile de ortaya konulması, raporlamada verilen sonuca güvenilirliği arttıracaktır. Bu karşılaştırmanın bilgisayar ortamında gerçekleştirilmesi tercih edilebilir.

$\mathrm{Bu}$ çalışmada, adli ayrıntıların sunulmasına önem verilmeksizin karbon kağıdı kullanılarak kopyalama içeren bir imza olgusu irdelenmiş, imzaların bilgisayar ortamında süperimpozisyonu yöntemi ile tetabukun gösterilmesi ve olgu üzerinden belge incelemede tetabuk ayırıcı tanısı ile birlikte bilgisayar teknolojilerinin rolünün tartışılması amaçlanmıştır. Teknik bir uygulamaya vurgu yapılmak istendiğinden, karbon kağıdı kullanarak kopyalama yönteminin basit bir kopyalama yöntemi olması çalışmanın zayıflı̆̆ 1 olarak değerlendirilmemiştir.

\section{Olgu Sunumu}

Olgumuzda davacı taraf, bir mağazadan alışveriş için imzaladığını belirttiği taksitli ödeme planı sözleşmesi için paradan sıfır atılması öncesinde 990.000.000TL borcu olduğunu ancak alacaklı tarafın sonraki süreçte bu borcun dışında 2400YTL'lik bir senedi de kendisinin imzaladığını belirterek haksız haciz işlemi başlattığını iddia etmektedir. Mahkeme tarafından kişinin eli ürünü imzası olup olmadığının değerlendirilmesi için gönderilen orijinal senet belgesi, kişinin eli ürünü imzasını içerdiğini belirttiği taksitli ödeme planı sözleşmesi ile karşılaştırmalı olarak incelenmiştir.

Gönderilen taksitli ödeme planı sözleşmesi (Resim1) üzerinde davalının ad ve soyadını belirten el yazısı ve üç adet imza; davaya konu orijinal senet (Resim 2) üzerinde ise el yazısı ve iki adet imza tespit edilmiştir. Fotokopi halinde gönderilmiş olan taksitli ödeme planı sözleşmesinin aslı olup olmadı̆̆ resmi olarak sorulduğunda belgenin aslının bulunamadığ belirtilmiştir. Bu nedenle üzerinde bulunan yazı ve imzada, bası izi, işleklik ve hız bakımından değerlendirme yapılamamıştır.

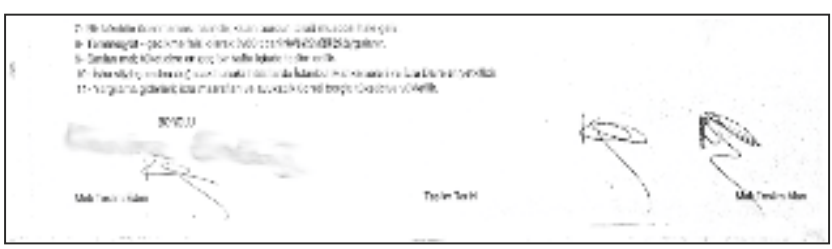

Resim 1.Davaya konu, aslı gönderilemeyen taksitli ödeme planı sözleşmesinin üzerinde bulunan 3 adet imza.

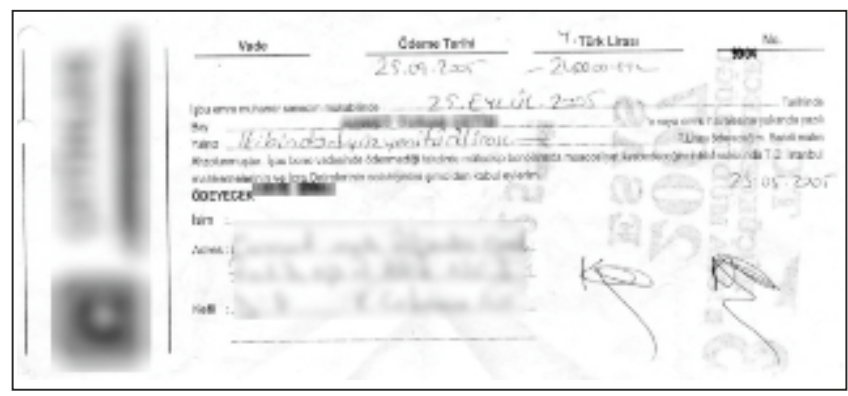

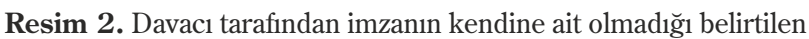
orijinal senet üzerinde bulunan 2 adet imza.

Karşılaştırma yapılacak olan imzalar incelendiğinde, senet üzerinde yer alan 2 adet imza ile taksitli ödeme planı sözleşmesinin sağ köşesinde yer alan 2 adet imza arasındaki birebir benzerlik dikkati çekmiştir. Tetabuk özelliği gösterip göstermediklerinin elektronik ortamda kanıtlanabilir şekilde incelenmesi için ilgili belgeler, oranları korunacak şekilde taranmış ve '.jpg' formatında kaydedilmiştir. Daha sonra ücretsiz ve açık kaynak kodlu bir program olan GIMP (GNU Image Manupulation Program) 2.8 programı ile 'Dosya' $\rightarrow$ 'Yeni' komutları ile açılan 'Yeni bir Görüntü Oluştur' penceresinden genişlik ve yükseklik değerleri belirlenmiş, 'Gelişmiş Seçenekler' menüsünden X ve Y eksen çözünürlükleri 300 yapılarak yeni ekran açılmıştır. Bir sonraki aşamada, 'Dosya' $\rightarrow$ 'Aç' komut basamakları ile karşılaştırma yapılacak olan birinci imza grubunun bulunduğu resim açılmış; açılan resim 'Dosya' $\rightarrow$ 'Dışa Aktar' komutları ile ulaşılan 'Görüntüyü Dışa Aktar' penceresinden dosya adı ve kaydedilecek konum belirlenmiştir. Dosya adı ve konum belirleme sonrasında, uzantısı '.png' yapılarak 'Dışa Aktar' butonu ve ulaşılan 'Export Images as PNF' penceresi ile yeniden 'Dışa Aktar' butonu tıklanarak dışarıya aktarma işlemi tamamlanmıştır (Resim 3).

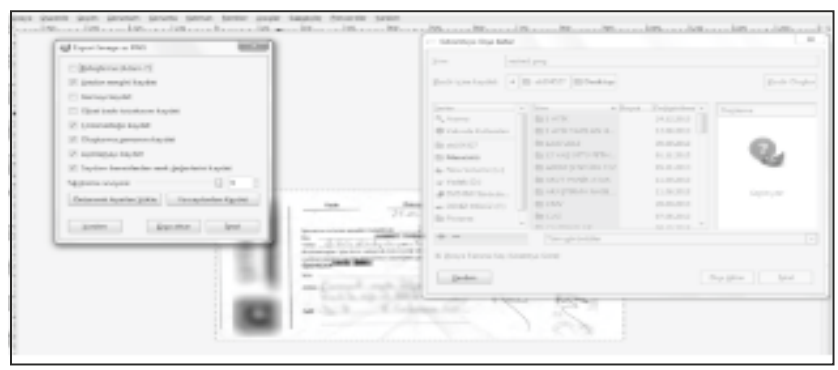

Resim 3.Karşılaştırması yapılacak olan senet üzerinde bulunan imzaların bulunduğu resmin dışa aktarılma işlemi 
İkinci imza grubunun bulunduğu konum ve ismi seçerek resmi açmak içinse, programda açık olan birinci imza grubunun bulunduğu resim üzerinde 'Dosya' $\rightarrow$ 'Katman Olarak Aç' komut basamakları ile karșılaștırma yapılacak olan ikinci imza grubunun konum ve ismi seçilmiştir. Bu arada, pencerenin yanlarında 'Araç Kutusu' ve 'Katmanlar' pencereleri 'Ctrl+B' ve 'Ctrl+L' tuşları ile önceden görünür hale getirilmiştir. Her iki dosya da, belirtilen şekilde açıldıktan sonra karşılaştırma yapabilmek için ikinci imza grubunun bulunduğu resmin 1şık geçirmezlik özelliği, 'Katmanlar' penceresinden 'Işık Geçirmezlik' değeri \%50'ye getirilerek azaltılmış ve 'Araç Kutusu' penceresi içinde bulunan 'Taşıma Aracı' seçeneği ile altta görünen ve karşılaştırma yapılacak olan birinci imza grubunun bulunduğu resimdeki imzaların üzerine doğru kaydırılarak getirilmiştir (Resim 4). Kaydırma işlemi tam uyum haline gelinceye kadar yapılmıştır (Resim 5). İmzalar arasında bir eksen değişikliği olup olmadığını değerlendirmek amacıyla 'Araç kutusu' penceresinden 'Döndürme Aracı (Ctrl+R)' ve 'Ölçeklendirme Aracı (Ctrl+T)' fonksiyonları kullanılarak kontrolyapılmıștır.

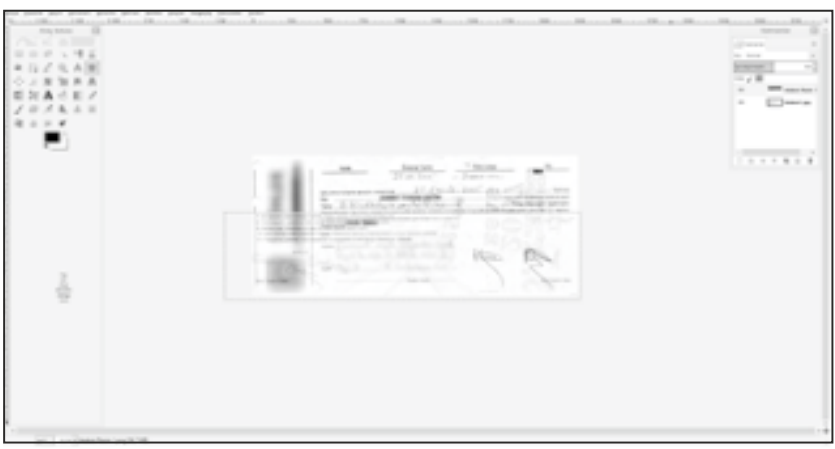

Resim 4.Karşılaştırması yapılacak olan imza gruplarının bulunduğu resimlerin ışı geçirmezliklerinin ayarlanması ve sonrasında kaydırma işlemi yapılarak uyumluluk değerlendirmesi.

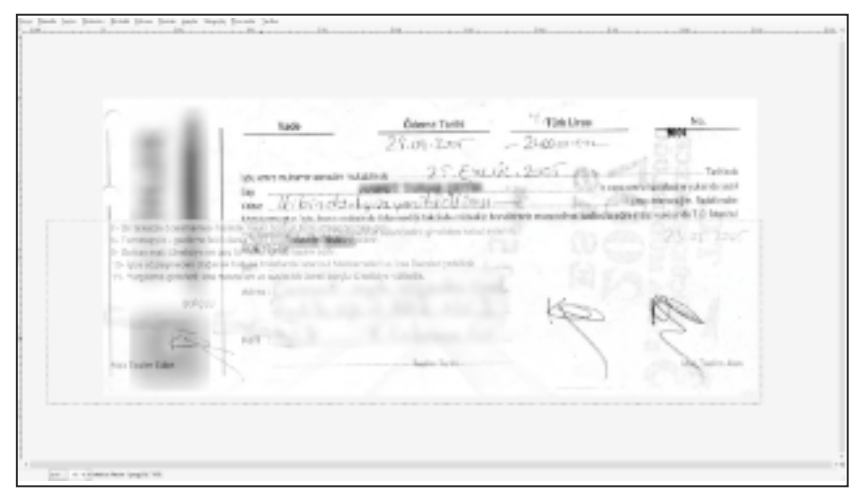

Resim 5. Ișıı geçirmezlik ayarı ve kaydırma işlemleri sonrası imza grupları arasındaki, hayatın doğal akışı ile uyuşmayacak derecedeki uyumun gösterilmesi.

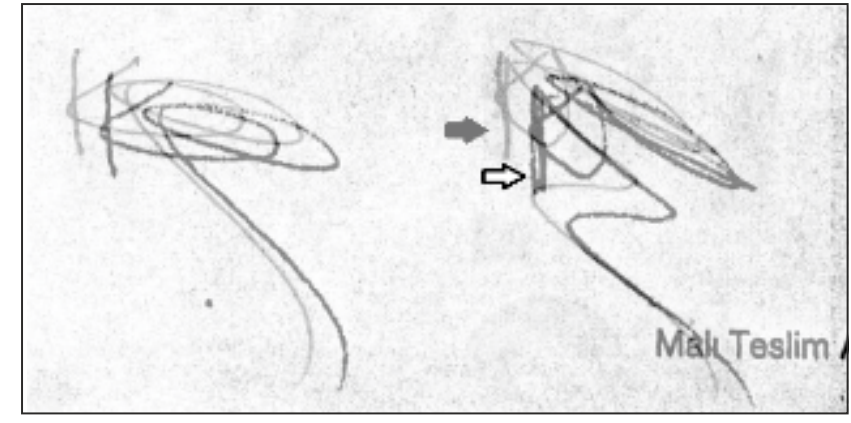

Resim 6. Orijinal belgedeki imza (mavi renkli) üzerinde kalemin mürekkep bırakamaması nedeniyle belirgin görünmeyen çizgi unsurunun kopya imza üzerinde belirgin olarak gözlemlenmesi.

Belgelerin incelenmesi sonucunda, farklı iki belgede tüm özellikleri ile aynı olan iki imza tespit edilmiştir (Resim 5). Orijinal belgede kalemin mürekkep bırakamaması nedeniyle imza üzerinde belirgin görünmeyen çizgi unsuru kopya imza üzerinde belirgin olarak gözlemlenebilmiştir (Resim 6).

Ayrica, inceleme konusu senette atılı imzalar ile davacinın karşılaştırma imzaları arasında tersim tarzı, işleklik derecesi, istif, eğim, doğrultu, seyir, hız, bası derecesi ve alışkanlıklar gibi tanı özellikleri bakımından uygunluk ve benzerlikler saptandığından söz konusu imzaların davacının eli ürünü olduğu ve inceleme konusu senet üzerinde saptanan imzalar ile yazıların farklı nitelikte kalemler ile yazılmıș olması, senedin başka bir belgeden kopartılmış olması ve sözleşme fotokopisi ile senette atılı imzaların birbirinin karbon nüshası olması nedeniyle söz konusu belge aslında mevcut olan boşlukların doldurularak söz konusu senedin oluşturulmuş olduğu, senet ile sözleşme içeriklerinin farklılığından dolayı kişinin imzalarının senet içeriği yazıları onaylar nitelikte olmadığ kanaatine varılmıstır.

Sunduğumuz bu olgu üzerindeki esas rapor kararının, orijinal senet belgesinin yanıltıcı doldurulması ve imzanın yazılı bilgileri onaylar nitelikte olmaması üzerinden verilmiş olduğu ve orijinal senet belgesindeki imzaların davacı tarafından atıldığı düşünüldüğünde, alacaklıların aynı imzaları neden zaten bir kere imzalanmış olan taksitli ödeme planı üzerine karbon kopya ile geçirmek isteyebilecekleri sorusu adli olarak takip edilebilecek konu başlıkları olmakla birlikte, bu olgu sunumunda hedeflenen tetabuk özelliği olan sahte imzaların elektronik ortamda kanitlanabilir verilerle ve ekonomik olarak değerlendirilmesini göstermek olduğundan tartışma bölümü de bu yönde sürdürülmüștür.

\section{Tartıșma ve Sonuç}

El yazısının bir çeşidi olan imzanın incelenmesinde; imzanın tersimi, işleklik derecesi, istif (sıkışıklık), eğim, doğrultu, hız, alışkanlıklar, bası derecesi, düzenlilik ve 
devamllık gibi özelliklerine bakılmaktadır $(1-4,7,12)$. Tüm bu özellikler değerlendirilirken imzanın oluşturulmasında kullanılan materyal de önemlidir. Bu materyaller kalem, fotokopi makinesi, yazıcı, baskı makinesi ve bunların tatbik edildiği kâğıt olarak sayılabilir $(3-7,13)$. Tümü birlikte değerlendirildiğinde daha sağlıklı bir sonuç elde edilebilir.

Ayrıca, bir kişinin, tüm özellikleri ile birbirinin aynı olan iki imzayı, farklı belgelere atabilmesi mümkün görülen bir durum değildir. Bu durum genellikle üstten gitme, karbon kağıdı kullanılarak kopyalama ve elektronik ortamda taranarak belgeye transfer yöntemi ile yapılan sahteciliklerde görülmektedir $(1,10,11)$.

Karbon kağıdı kullanılarak kopyalama ile yapılan imza sahteciliği yönteminde, orijinal belge üzerinde büyütme ile yapılan incelemelerde imza üzerinden gitmeye dair bulgular, kopya imza üzerinde ve/veya çevresinde karbon varlığı, iletilmiş ışık ile büyütülerek yapılan incelemelerde renk partiküllerinin kalem yönü ile hep aynı yönde değil her yönde olması, yan ıșık ile büyütülerek yapılan incelemelerde silgi izleri ve genellikle daha iyi kontrast oluşturmuş bir kopya imza dikkati çekebilir. Ancak, bu bulguların tespit edilememesi de mümkündür $(11,14,15)$.

Elektronik ortamda taranarak transfer yolu ile yapılan imza sahteciliği yönteminde, olağan durumda imzada olması gereken özelliklerden ıslak halin bulunmaması, bası izinin olmaması ve elektronik yazı aracı tarafından oluşturulabilecek lekelenmeler ve/veya silinmeler gibi artefaktların varlığı, ayrım yapmada önemli olacaktır. Detaylı inceleme ile görülebilecek olan hız, bası izi ve işleklik gibi önemli sayılan tanı unsurları bu yöntemde de kaybolarak değerlendirilemez hale gelebilecektir $(3,4,6,7,9,12)$.

Tüm bu bilgiler birlikte değerlendirildiğinde, olgumuzda, her ne kadar elimizde bulunan fotokopi belge nedeniyle zaten hız, bası izi, işleklik gibi önemli sayılan unsurlar ve karbon kağıdı kullanarak kopyalama tespitine dair yukarıda belirtilen olası diğer unsurlar değerlendirilememiş olsa da, üst üste tetabuk eden imzaların bilgisayar programı ile tespiti sonrasında orijinal imzadan kopyalamanın karbon kağıdı mı, elektronik ortamda transfer ile mi yapıldığının ayırıcı tanısı, orijinal senetteki imza atılırken kullanılan kalemden mürekkep akmasında eksiklik oluşmuş olmasına rağmen kopyalanmış belgede o imza bölümünün tam çizgi halinde görülmesi değerlendirilerek yapılmıştır. Bu durum basıda oluşturulan güce bağlı olarak, mürekkepten bağımsız şekilde, karbon kağıdı kullanılarak kopyalamada görülebilmektedir. Çünkü karbon kağıdı kullanılarak kopyalamada kopya imza orijinal imzadaki mürekkep özellikleri ve dağılımından bağımsız olarak basıda oluşturulan güç miktarına göre şekillenmektedir (15).
Üstelik, taksitli ödeme planı sözleşmesinde davacının kabul ettiği en az bir ıslak imza unsuru anıldığından belgenin aslının bulunması gerektiği düşünülmesine ve sorulmasına rağmen alacaklı tarafın şirket arşivlerinde belgenin aslının bulunamadığının belirtmesi en azından belgenin sağında karbon kağıdı kullanılarak kopyalandığı düşünülen iki imza açısından adli olarak ta sahtecilik ihtimalini arttırmaktadır. Orijinal senet üzerinde yer alan imzanın büyütülerek değerlendirilmesinde imzanın üzerinden gidilmeye dair herhangi bir ekstra ize rastlanılmamış olmakla birlikte orijinal imzanın fotokopisinin çekilerek o kalıbın üzerinden gitmek şeklinde model oluşturulabilmesi de mümkün olduğundan veya karbon kağıt kişinin kendi imzasını attığı anda orijinal belgenin altında saklı olarak tutulmuş olabileceğinden, üzerinden gitme bulgusunun tespit edilmemesi bir tanı değeri taşımamıştır.

Ancak, bazen hız, bası izi ve işleklik gibi unsurlar yazıda varken bile sahtecilik iddiaları ortaya atılabilmektedir. Yukarıda bahsedilen karbon kağıdı kullanılarak kopyalama yöntemi ile ya da görüntünün tarandığı fotokopi ve baskı makineleri ile oluşturulmuş üst üste tetabuk eden sahte imzaların yanı sıra yazı-imza makinesi ile birebir aynı ya da varyasyonlar içeren imza oluşturma kavramları da güncel bilimsel tartışma konuları arasındaki yerini korumaktadır. Bilimsel yazılardan çok kitap, farklı yayın türleri ve internet sitelerinde yer bulan yazı imza makineleri tarihi 1803'lere dayandırılmaktadır (16-21). Yukarıda sayılan parametrelerden fulaj hariç diğerleri tartışmasız olmakla birlikte, fulaj varlığı, yokluğu ya da -var olması durumunda bile- fulajlarda oluşan farklılık nedeni ile imza makinelerinin attığ 1 imzaların uzmanlarca tanınabileceğini öne süren bilim adamları bir yanda; baskı miktarını ve her farklı imza atışta oluşabilecek varyasyonları bile ayarlayabilen imza makinelerinin bulunduğunu iddia eden bilim adamları bir yanda yer alarak, ülkemizde ve dünyada tartışmalar sürmektedir. Ne yazık ki 'autopen', 'signing machine', 'signature machine', 'robot pen', 'forensic', 'document examination', 'fake', 'forgery' gibi ifadelerin 20'den fazla kombinasyonu denenerek yapılan aramalarda direkt yazı-imza makinesi ile ilişkili bir yayına ulaşılamamıştır. Bu konuda uğraşılı aramalara rağmen literatürde rastlanmamış olması; en azından metaanaliz yaparak bir yargıya varmayı sağlayacak yaygınlıkta çalışmaların bulunmadığını düşündürmektedir. Bu nedenle, konu farklı bilim insanlarının ancak yorumları seviyesinde tartışılabilmektedir

Karbon kağıdı, fotokopi makinesi, yazıcı, baskı makinesi ya da yazı-imza makinesi seçenekleri halinde birebir imza sahteciliğinin kontrolü için GIMP ile karşılaştıııldığında çok daha karmaşık faktörleri inceleyen SVD (Singular Value 
Decomposition), N-Tuple Learning, SVM (Support Vector Machine), LCSS (Longest Common Subsequence), DTW (Dynamic Time Warping), LPC (Linear Prediction Coding), Movalyzer, ASV (Automatic Signature Verification) gibi yazı analiz sistemleri kullanılabilmektedir (22-27). Bu sistemler temel olarak MRF (Markov Random Field Based) denilen basılı yazı, el yazısı ya da cihaz artefaktlarının oluşturduğu geometrik şekilleri karşılaştırarak (28-33), tekil vektörler üzerinden maksimal enerjili bir matrikste alt alanların birbiri ile oluşturdukları açıları karşılaştırarak (22), kalem yükseklik açıları, kalem ucunun $x-y$ eksenindeki koordinatları, kalem ucu basıncı gibi karşılaştırmalarla (23), kalem ucu koordinatlarının imza zamanlarıyla karşılaştırılması (24) ya da nöral ağ yöntemleri (25) gibi yöntemlerle işlemektedir. Bu sistemler, BIOMET, PHYLIPS, MCYT, Extended SIGMA, SVC 2004 gibi veritabanlarını kullanabilmektedir $(24,30,34)$. Bu sistemlerden SVD için \%1,2'den az, LPC için de \%4'ten az hata payı sonuçları bildirilmiştir. Hata payı oranını, belgenin dijital sistemlerle değil, belge inceleme uzmanı gözüyle incelendiği serilerde de $\% 3,4$ sonucu yer alabildiği gibi 3100'de 224 yanlış karar, 1622 karar verilememiş vaka gibi sayılar da farklı yayınlarda sunulmaktadır. Ayrıca, yapılan bazı çalışmalarda kaligrafların belge inceleme uzmanlarını 'sıradan taklitçiler'e göre 4 kat daha fazla aldatabildikleri, belge inceleme uzmanlarını $\% 3,4$ hata payı ile inceledikleri belgeleri 'sıradan inceleyici'ler karşılaştırdığında hata payının \%19,3’e kadar yükseldiği ve fotokopi belgeler için belge inceleme uzmanları arasında bile karar bildirememe oranının \%22'ye kadar çıkabildiği belirtilmektedir (35-37).

Sonuç olarak, belge incelemede en ideal sonucun yetkin bir belge inceleme uzmanının değerlendirmesi eşliğinde yukarıdaki sistemlerden birini içeren bir bilgisayar programı kullanılarak alınabileceği öne sürülebilir. Ama her laboratuvarın yüksek lisans ücretleri ile satın alınabilecek büyük programları edinmesi ve bazı veritabanlarını kullanması ekonomik açıdan mümkün olmamaktadır. Bu nedenle, daha basit ama ücretsiz, açık kaynak kodlu programların da tetabuk gibi sahtecilik unsurlarının değerlendirilmesinde kullanılabileceğini göstermek açısından benzer yeni olguların ve değerlendirilme biçimlerinin yayınlanması marka tekelciliğinden uzak bilimsel yaklaşım için teşvik edilmelidir. Ayrıca, belge incelemede yetkinliğin ülkemizde ve dünyada birçok ülkede tanımlanmış formel kriterleri bulunmadığından, belge inceleme yetkinliğinde de net kriterler oluşturularak bilimsel yaklaşım sağlanmalıdır.

\section{Kaynaklar}

1. Birincioğlu İ, Özkara E. Adli belge incelemelerinde bilinmeyenler, örneklerle yazı ve imza analizi ile ıslak imza kavramı. TBB Dergisi. 2010;87:403-33.

2. Aşıcıŏlu F. Adli Belge İncelemesi. İstanbul: Beta Basım Yayım Dağıtım A.Ş., 2005: 61-7.

3. Sala S, Karslı Ö, Kıymaz L. Belge İncelemeleri. In: Cihangiroğlu B, editör. Adli Bilimler 1. Ankara: Jandarma Kriminal Daire Başkanlığı Yayınları, 2011: 269-349.

4. Alkan N. Adli Bilimlerde El Yazısı ve İmza İncelemeleri. In: Aşıcıŏ̆lu F, editör. İmza Sahtecilikleri. İstanbul: Öner Matbaacilik, 2007: 148-57.

5. Yılmaz R. Tibbi Belgelerde Yapılan Sahtecilikler. Uzmanlık tezi. Adalet Bakanlığ 1 Adli Tip Kurumu Başkanlığı. İstanbul: 2003.

6. Yilmaz R, Birincioğlu İ, Bütün C, Günaydın U, Yılmaz S. Pul nakli ile yapılan imza sahteciliği: olgu sunumu. Adli Tıp Bülteni. 2004;9(3):91-5.

7. Aydoğdu E, Ataç Y. İmza sahteciliğinin türleri, tespiti ve önlenmesi. Turkish Journal of Police Studies. 2011;13(2):49-71.

8. Yılmaz R, Koç S. Adli belge incelemeciliğinin dünyadaki tarihsel gelişim (II). Turkiye Klinikleri J Foren Med. 2006;3(3):101-6.

9. Hamzaoğlu N, Yavuz F, Çakır İ. Üzeri kaplanmış yazıların spektral ve hiperspektral yöntemlerle analizi. Journal of Forensic Medicine. 2008;22(3):22-34.

10. Birincioğlu İ, Kurtaş Ö, Çakır İ, Toprak S. El yazısı incelemelerinde hız kavramı. 6. Anadolu Adli Bilimler Kongresi; 6-9 Eylül 2007 Sözel ve Poster Bildiriler Kitabı, Celal Bayar Üniversitesi Matbaas1, Manisa 2007;121-4.

11. Mane M. Signs of traced signature in forgery. IJAR. 2014;4(6):2135.

12. Birincioğlu İ. Örneklerle El Yazısı İnceleme Teknikleri ve Prensipleri. In: Aşıcıoğlu F, editor. İmza Sahtecilikleri. İstanbul: Öner Matbaacilık, 2007: 122-47.

13. Yılmaz R, Koç S. Adli belge incelemeciliğinin tarihsel gelişimi (I). Turkiye Klinikleri J Foren Med. 2006;3(2):72-8.

14. Mathyer J. The expert examination of signatures. J Crim L Criminology \& Police Sci. 1961;52(1):122-33.

15. Lin SF, Chang YW, Su CK. A study on Chinese carbon-signature recognition. J Inf Sci Eng. 2002;18(2):257-80.

16. Autopen. Erişim adresi: http://en.wikipedia.org/wiki/Autopen. Erişim tarihi: 09/01/2014.

17. 10 facts about the autopen. Erişim adresi: http://www. politico.com/story/2013/01/autopen-barack-obama-10-facts85720.html. Erişim tarihi: 09/01/2014.

18. When a robot signs a bill: a brief history of the autopen. Erişim adresi: http://www.nationaljournal.com/whitehouse/when-arobot-signs-a-bill-a-brief-history-of-the-autopen-20130103. Erişim tarihi: 09/01/2014.

19. Hamilton C. The Robot That Helped To Make A President: A Reconnaissance Into the Mysteries of John F. Kennedy's Signature. New York: Charles Hamilton Autographs, 1965.

20. Popular Mechanics Magazine 1937;67(5):657. Erişim adresi: $\mathrm{http}: / /$ books.google.com.tr/books?id=_toDAAAAMBAJ\&pg=PA $657 \& \mathrm{dq} \# \mathrm{v}=$ onepage\&q\&f=false. Erişim tarihi: $09 / 01 / 2014$.

21. Automated signature technology. Erişim adresi: http://www.signaturemachine.com. Erişim tarihi: 09/01/2014.

22. Kamel NS, Sayeed S, Ellis GA. Glove-based approach to online signature verification. IEEE Trans Pattern Anal Mach Intell. 2008;30(6):1109-13.

23. Maneechot T, Kitjaidure Y. Signature Verification Using N-tuple Learning Machine. Conf Proc IEEE Eng Med Biol Soc. 2005;3:2794-7.

24. Gruber C, Gruber T, Krinninger S, Sick B. Online signature verification with support vector machines based on LCSS kernel functions. IEEE Trans Syst Man Cybern B Cybern. 2010;40(4):1088-100. 
25. Wu QZ, Jou IC, Lee SY. On-line signature verification using LPC cepstrum and neural networks. IEEE Trans Syst Man Cybern B Cybern. 1997;27 (1):148-53.

26. Mohammed LA, Found B, Caligiuri M, Rogers D. The Dynamic Character of Disguise Behavior for Text-based, Mixed, and Stylized Signatures. J Forensic Sci. 2011;56(1):136-14.

27. Brault JJ, Plamondon R. A Complexity Measure of Handwritten Curves: Modeling of Dynamic Signature Forgery. IEEE Trans. Syst. Man Cybern. 1993;23(2):400-13.

28. Zheng Y, Li H, Doermann D. Machine printed text and handwriting identification in noisy document images. IEEE Trans Pattern Anal Mach Intell. 2004;26(3):337-53.

29. Bicego M, Murino V. Investigating Hidden Markov Models' capabilities in 2D shape classification. IEEE Trans Pattern Anal Mach Intell. 2004;26(2):281-6.

30. Van Bao L, Garcia-Salicetti S, Dorizzi B. On using the Viterbi path along with HMM likelihood information for online signature verification. IEEE Trans Syst Man Cybern B Cybern. 2007;37(5):1237-47.

31. Thakoor N, Gao J, Jung S. Hidden Markov model-based weighted likelihood discriminant for 2-D shape classification. IEEE Trans Image Process. 2007;16(11):2707-19.
32. Argones Rúa E, Alba Castro JL. Online Signature Verification Based on Generative Models. IEEE Trans Syst Man Cybern B Cybern. 2012 Apr 4. [Epub ahead of print]

33. Zheng Y, Li H, Doermann D. Machine printed text and handwriting identification in noisy document images. IEEE Trans Pattern Anal Mach Intell. 2004;26(3):337-53.

34. Ahmad SM, Ling LY, Anwar RM, Faudzi MA, Shakil A. Analysis of the effects and relationship of perceived handwritten signature's size, graphical complexity, and legibility with dynamic parameters for forged and genuine samples. J Forensic Sci. 2013;58(3):724-31.

35. Sita J, Found B, Rogers DK. Forensic handwriting examiners' expertise for signature comparison. J Forensic Sci. 2002;47(5):1117-24.

36. Dewhurst T, Found B, Rogers D. Are expert penmen better than lay people at producing simulations of a model signature? Forensic Sci Int 2008;180(1):50-3.

37. Found B, Rogers DK. Investigating forensic document examiners' skill relating to opinions on photocopied signatures. Sci Justice. 2005;45(4):199-206. 